\title{
Research on the Platform Construction of Innovative and Entrepreneurial Talent Cultivation in Universities
}

\author{
Ren Song \\ Information Management Center, \\ Jilin University of Finance and Economics, \\ Jilin, China. \\ E-mail: 9860543@qq.com
}

\author{
Yang Liu \\ Institute Of Management science and Engineering, \\ Jilin University of Finance and Economics, \\ Jilin, China \\ E-mail: 7923759@qq.com
}

\begin{abstract}
The platform of innovative and entrepreneurial talent cultivation in Universities is helpful for students to have a preliminary understanding of the modern enterprise management and business model. So the simulation of the economic environment is not only significantly help to cultivate students' ability of independent innovation and entrepreneurship, at the same time, it also has a great improvement on students' professional ability, team spirit, cooperation and communication, business decision-making. Therefore, to build an innovative and entrepreneurial talent training platform in Colleges and universities, play an important role in training cross disciplinary talents and innovative talents.
\end{abstract}

Keywords-innovation and entrepreneurship; interdisciplinary; practice teaching; personnel training mode

\section{SIGNIFICANCE OF THE PLATFORM CONSTRUCTION OF INNOVATIVE TALENTS TRAINING IN COLLEGES AND UNIVERSITIES}

Along with the development of social economy and the progress of science and technology, our country should move to the developed countries, enterprises increasing high demand on extensive knowledge and $\mathrm{T}$ type professional skilled talent, so social requirements for college graduates have also increased. However, due to the reform of the education system, a large number of college enrollments, college graduates into the community, resulting in $\mathrm{T}$ type talent competition, Great employment pressure of college graduates.

For all university, the practical course is a very important procedure of the study during their undergraduate period. However, due to various reasons, it is difficult for students to contact with the core content of the professional knowledge; it is unable to understand the development of the enterprise and the market. The students in the practice work of giddy and insincere, boring, enthusiasm is not high, it is difficult to acquire knowledge for actual work. Therefore, the practice of college graduates training is an urgent problem to be solved. To build a new talent training platform, we need to explore, research, improve.

The construction of innovative and entrepreneurial talent training platform can effectively change the teaching mode and improve the teaching quality. This practice teaching mode can achieve the desired results; will show a good demonstration effect in the country. At the same time, developed in the platform of $\mathrm{T}$ Talents once into the society, they will have more complete life planning and of them to be engaged in business has a more clear understanding, which will for the development of the state and society to a more active role. Therefore, the construction of innovative entrepreneurial talent training platform for the development of the country's society has important significance.

\section{THE MAIN CONTENTS OF THE TRAINING PLATFORM FOR INNOVATIVE AND ENTREPRENEURIAL TALENTS IN COLLEGES AND UNIVERSITIES}

The revolution of the mode of university personnel training has been regarded as the fundamental driving force of the national progress by many scholars in the educational circles in many countries [1]. Youth is a special group to create value for the state and society, they are responsible for the future development of the country, is also the object of national key cultivation. At present, this is full of opportunities and challenges of the society, the rapid economic development, resulting in increased labor innovation skills. According to the principle of creation being originated from practice and innovation applied to and ends in practice, to improve the students' innovation consciousness and practical ability and learning ability, comprehensive professional ability, but also for the state and society and alleviating the urgent needs of the college students' employment [2]. Education itself is not to impart knowledge, but to allow the development and application of knowledge. Reasonable talent training mode is not only to improve the students' learning interest, but also to stimulate students' potential.

China's famous professor Pan Maoyuan says: "A modern specialized talented person, must have the following several aspects of knowledge structure. First, relatively generous basic knowledge; Second, a certain depth of expertise; Third, the general 'frontier' knowledge, that is, to understand the dynamic trends of specialized subjects and related disciplines, the important new achievements in science and new problems; Fourth, the necessary knowledge of the horizontal disciplines and scientific methodology; Fifth, the general basic cultural knowledge, or have no direct contact with the professional school but is conducive to expanding horizons and explore ideas and improve the cultural quality of certain knowledge. 
The most general goal is to handle the relationship between the breadth and precision, and to achieve the comprehensive application of proficiency." [3].

University innovation and entrepreneurship personnel training platform is a multi - disciplinary platform. The platform takes the manufacturing industry as the main driving force, the trade economy competition as the auxiliary driving force, the service industry is the aid driving force, and forms a simulation integrated system. Platform is to build a real business environment from the perspective of, through the simulation of the service industry and the manufacturing industry, construct to production, sales, supply, demand, competition and so on are intertwined and interdependent and co existent virtual market economy innovation and entrepreneurial talent culture. Different students play different roles in this platform, each of which is determined by the students themselves, each of the student's business decisions will affect their business development progress, each business is also personally negotiated and personally communicate by the students themselves, students to experience the responsibility of each position, Also let the students personally feel the collective strength of a team. In this platform, the industrialization, informatization and industrialization together, to form a comprehensive and diversified environment. At the same time, the business, management, accounting, finance, taxation and other professional operations are integrated together, mainly to the enterprise manufacturing and enterprise management as the core business, extending to other Service Corporation, the formation of a demand supply chain.

In this small virtual economic market, students can be based on their own learning professional in this platform to simulate different roles, so that students feel the reality of the work environment, and the responsibility of a staff. At the same time, in this virtual economic market, by training students to the initial awareness of the enterprise and the internal management of enterprises and enterprises with the outside company's business, students can strengthen the management of thinking, the overall concept and team spirit; expand the students' professional ability, practical knowledge and comprehensive quality. Let students to understand the overall framework of enterprise management, familiar with the working environment of enterprise production and manufacturing, to understand the work of the enterprise, to establish a practical basis for the employment of students. The platform to the teaching of the form of the game, so that students participate in the practice of learning, so that students are interested and willing to participate in the environment.

The core value of the innovative and entrepreneurial talent training platform is to establish a platform for teaching and learning. In this platform, to achieve industrial awareness, so that students learn in the environment. To realize the participation of enterprise management, so that students in the competition thinking. To achieve business objectives, so that students in the action of cognition. To achieve emphasis on team exploration, so that students in the organization of cooperation.

\section{THE MAIN TECHNOLOGY OF THE CONSTRUCTION OF INNOVATIVE AND ENTREPRENEURIAL TALENT CULTIVATION PLATFORM IN UNIVERSITIES}

University Innovation and entrepreneurship personnel training platform mainly uses the Java+JSP language development; data storage using orcale database, the interface uses the 3D effect. Server using the win2003Server version of the system, the student terminal using winXP system.

Oracle database is currently the most widely used database system has the highest security level and the most mature technology. The core function of the large scale system is accomplished by using the stored procedure of the database, which greatly improves the performance and speed of the system.

Using Java language as the main development language of the platform, the main reason is because it is stable and safe, platform-independent and portable. Multi-threaded functions is the advantage of Java language allows computers to handle several tasks at the same time, it just meets the requirements of the platform for the need of multi module at the same time, and this is another reason to use Java language as the main development language.

\section{THE MAIN RESEARCH METHODS OF THE CONSTRUCTION OF INNOVATIVE AND ENTREPRENEURIAL TALENTS TRAINING PLATFORM IN UNIVERSITIES}

The training platform for innovative and entrepreneurial talents in Colleges and universities is a multi - disciplinary platform, in the platform package a lot of modules, such as learning resources module, module of contract, actually a single module, module of enterprise competitiveness, market supply and demand module, and enterprise manufacturing module, module of trade and financial software module. In the operation of the platform, the storage process is used to make the platform more secure. The most advantage of the stored procedure is to allow the modular program design, the implementation of fast speed, good security, reduce network traffic.

For the innovation and entrepreneurship training platform in a business request, may involve a number of database calls, repeatedly check the same database table or a different database table, if the database is not open and closed in time, then it will cause the scarcity of connection resources, inefficient operation. Using the stored procedure to process the application order, to ensure that the database of a service request is processed in the message queue, each call database can open the database connection in time, also can close the database connection, reduce the network overhead, reduce the occupation of memory resources, and improve the efficiency of the operation.

Oracle database storage process is its own system functions, without the developer to do complex processing. In the platform, for a batch application request, the number of accesses to the database is $\mathrm{N}$, at this time, the Java program will use the multi thread to call the database, call the message 
queue processing, still does not affect the network resource occupation, memory resources. The larger batch request, the more able to reflect the high performance of the Oracle database.

Message queue should be a single thread message queue, there are also multi thread message queue. We take a single thread message queue to illustrate. Single thread specific message queue only allows an insert operation is executed at the end of the queue (tail), delete operation is executed at the head of the queue (head). This is similar to the method of queuing in reality, the first elements in the queue leaves the queue firstly. The newly added elements at the end of the queue, which is queue by order of first in, first out. To create a message queue, you need to initialize a queue, that is, the definition of an empty queue, the queue of the head pointer and tail pointer were set to 0 . When there is an element of $X$ to join the queue, the first to determine whether the queue is full, if the queue is full, then return failure message, if the queue is not full, then insert element $\mathrm{X}$ to the position specified by the tail pointer (tail), and then tail +1 . The entire message queue has been circulating to determine the length of the message queue, if the message queue is not empty, the header pointer is taken out of the current element, waiting for the other processing, and then delete the current element, head +1 . Determine whether the message queue is empty, that is, if the pointer is equal to the tail pointer, that is, whether the length of the message queue is zero. To determine whether the message queue is full, that is, that is to check whether the value of maxSize is the same as the tail pointer.

When the position of the queue's tail is marked, that is, the first $M$ position is exactly equal to the length of the queue, the queue will be prompted to overflow, Even if there is an empty position in the front of the queue. In order to save space, we can connect the head and the tail of the queue, the queue becomes circular linked list, so that the space can be reused. As shown in Figure 1.

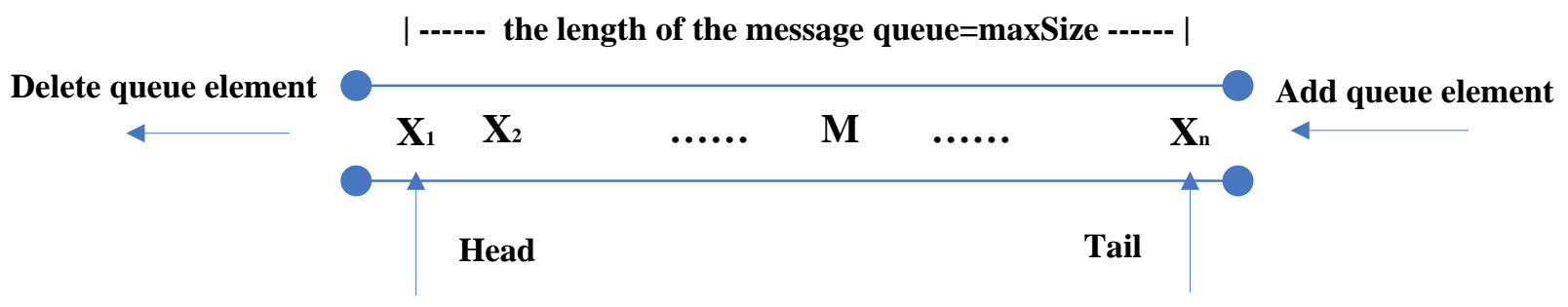

Figure.1. A single thread message queue

\section{THE FINAL GOAL OF BUILDING THE INNOVATION AND ENTREPRENEURSHIP TALENT TRAINING PLATFORM IN COLLEGES AND UNIVERSITIES}

University Innovation and entrepreneurship personnel training platform has resource model, contract model, single model, enterprise competitiveness model, market supply demand model, and so on, set up government services, business services, public services and other services. The platform can be used to adjust the parameters to achieve different levels of difficulty, different levels of training, for different majors, different grades of students can use different parameters to participate in training. Students in the platform to be able to get business creation, business decisions, job skills and information system operation and other aspects of the training, understanding human resources business management rules, financial management rules, market development rules, the professional and financial software, manual do account, bank loans and other professional practice has also been a certain degree of training [4]. So that students in the real step into the community before there is a preliminary understanding of their own life, so as to plan their own life, which is a good foundation for the country to cultivate the $\mathrm{T}$ talents with economic characteristics. Let the students have a good learning experience before employment; have a warm working attitude to accept the real work.

\section{ACKNOWLEDGEMENT}

This research was financially supported by Jilin Provincial Association of Higher Education (Project Number: JGJX2015D117), major program of E-commerce Practice Teaching System Driven by Creativity, Innovation, Self-business Initiation.

\section{REFERENCES}

[1]. Huang Benxiao, Huang Rui, 'College students' innovation and entrepreneurship practice platform for the construction of literature review", Productivity research, vol.1, pp. 140-145, 2014.

[2]. [2] Wang Ye, Zhu Xiaoqing, "Construction and practice of innovation and entrepreneurship training platform for college students", Contemporary educational practice and teaching research: electronic journal, vol. 9, 2015.

[3]. Shen Wei, Li Yingnan, "The construction of the training mode of compound talents in Colleges and universities", Journal of Shenyang Normal University: Social Science Edition, vol.32, pp. 89-91, Mar., 2008.

[4]. Huang Hairong, "Discussion on the construction of the training base for economic and trade majors in the school training base", Journal of Chongqing Industry and Trade Polytechnic, vol.1, 2012. 